\title{
CUIDADOS COM OS BEBÊS: \\ O CONHECIMENTO DAS PRIMÍPARAS ADOLESCENTES
}

The care with babies :

the knowledge of the teenagers primiparas

Cuidados con los bebés:

el conocimiento de las primíparas adolescentes

Dayane Cristina de Sousa Rocha

Maria Gorette Andrade Bezerra

Antonia do Carmo Soares Campos

\section{Resumo}

0 bem-estar dos bebês nascidos de mães adolescentes foi o incentivo para a realização desta pesquisa que objetivou investigar se as gestantes adolescentes primíparas estão recebendo orientações acerca do cuidado com seus bebês. Estudo descritivo, com abordagem quantitativa, no qual se utilizou como técnica para a coleta de dados a entrevista estruturada, nos meses de setembro e outubro de 2004. Teve como cenário o Alojamento Conjunto de uma maternidade na cidade de Fortaleza, considerada de referência terciária no Estado do Ceará. A amostra ficou constituída de 30 adolescentes primíparas, com idade entre 13 e 19 anos, baixo grau de escolaridade e evasão escolar; baixa renda familiar; união estável e que não realizaram o número de consultas de pré-natal preconizadas pelo Ministério da Saúde. Teve-se como resultado o baixo déficit de orientação das primíparas adolescentes acerca de como cuidar do bebê, que esperam contar com a ajuda dos pais e familiares. Constatou-se ainda que, apesar de realizarem o pré-natal, faltou interesse em participar das palestras oferecidas.

Palavras-chave: Cuidado da Criança. Conhecimento. Gravidez na Adolescência.

\section{Abstract}

The well-being of babies born from adolescent mothers was the motivation to carry out this research that aimed to in investigate if primipara pregnant adolescents are receiving orientations about the care with their babies. Descriptive study with quantitative approach, in which one used as technique for data collection the semi-structured interview, in the months of September and October, 2004. Had as a scenario the shared accommodation of a public maternity ward in the city of Fortaleza, considered as a tertiary reference in the state of Ceará. The sample was composed of thirty primipara adolescents between 13 and 19 years of age, low education and school evasion; low family income; stable union and that did not carry out the number of prenatal consultations recommended by the Ministry of Health.We had as a result the low deficit of orientation of the primipara adolescents about how to take care of the baby and what they hope to count on the help of parents and relatives. We still found out that, in spite of doing the pre-natal, they did not show interest in participating in the lectures offered.

Keywords:

Child Care. Knowledge. Pregnancy in Adolescence.

\section{Resumen}

E bienestar de los bebés nacidos de madres adolescentes fue e incentivo para la realización de esta investigación que objetivó investigar si las embarazadas adolescentes primíparas están recibiendo orientaciones acerca del cuidado con sus bebés. Estudio descriptivo, con abordaje cuantitativo, en lo cual se utilizó como técnica para la colecta de datos la entrevista estructurada, en los meses de septiembre y octubre de 2004. Tuvo como escenario e Alojamiento Conjunto de una maternidad en la ciudad de Fortaleza, considerada de referencia terciaria en el Estado de Ceará - Brasil. La muestra se quedó constituida de 30 adolescentes primíparas, con edad entre 13 y 19 años, bajo grado de escolaridad y evasión escolar; baja renta familiar; unión estable y que no realizaron el número de consultas de prenatal preconizadas por el Ministerio de la Salud. Se hube como resultado el bajo déficit de orientación de las primíparas adolescentes acerca de como cuidar del bebé, estas esperan contar con la ayuda de los padres y familiares. Seconstató aunque, a pesar de que realicen el prenatal, faltó interés en participar de las charlas ofrecidas.

Palabras clave:

Cuidado del Niño. Conocimiento. Embarazo en Adolescencie. 


\section{INTRODUÇÃO}

A adolescência corresponde à fase de transição, entre a infância e a idade adulta, marcada por profundas abrangentes mudanças nos aspectos físico, psicológico e comportamental, com repercussões individuais, familiares e sociais. 0 quadro agrava-se quando a jovem engravida nesse período em razão de insegurança, medo e dúvidas próprias da idade. A adolescência compreende a faixa etária entre 10 a 19 anos $^{1}$.

Durante a adolescência, começa a ser evidenciada a sexualidade, período em que ocorre na maioria das vezes a primeira relação sexual. 0 início da puberdade e a menarca ocorre cada vez mais cedo e, com isso, a iniciação sexual torna-se cada vez mais precoce. 0 desconhecimento sobre sexualidade e saúde reprodutiva faz com que as adolescentes engravidem "sem querer".

Como enfermeiras de uma maternidade pública e docentes, atuando na área da Saúde da Mulher, o que temos observado é que as gestações, em sua maioria, são indesejadas. Com isso, as adolescentes costumam procurar o serviço de pré-natal tardiamente ou em número insuficiente de consultas, o que resulta em intercorrências na gravidez ${ }^{2}$.

A consulta do pré-natal tem como objetivo favorecer o relato da gestante sobre queixas, ensejar o esclarecimento das dúvidas, mensurar altura uterina e pressão arterial, auscultar os batimentos cardiofetais, avaliar o estado nutricional e realizar exames de rotina, com a finalidade de investigar anemia, infecções e o encaminhamento à imunização e à odontologia, quando necessário.

$E$ na vivência das autoras como enfermeiras, contudo, observou-se que, após o nascimento do bebê, quando as mães ficam internadas nas maternidades em sistema de alojamento conjunto ( $A C)$, ou seja, destinado a abrigar o binômio mãe e filho, surgem as primeiras dúvidas de como cuidar do bebê.

Com isso, notou-se que a futura mãe necessita receber orientações a respeito de como cuidar de seus bebês. Inicialmente, conhecer a fisiologia do recémnascido (RN), as mudanças na pele; a linguagem do choro que expressa fome, sede, dor, frio ou calor, fraldas molhadas, ou somente necessidade de segurança; como segurar e banhar o seu bebê; limpeza do coto umbilical; prevenir assaduras; e a importância de técnicas de amamentação. Além desses cuidados, é importante que a mãe tenha conhecimento das patologias mais comuns do RN, como evitá-las e a relevância da vacinação e da puericultura; as cólicas que provocam episódios de choro intenso e que duram minutos ou horas e apavoram as mães, pois algumas crianças com cólicas têm exame físico normal, mas em outras a causa pode ser alimentação insuficiente, otite média, hérnia inguinal, alergia alimentar e outras. Podem surgir também, regurgitação e vômitos, lesões na região das fraldas, dermatites, problemas do umbigo, fimose e parafimose, constipação intestinal e outros.

Todo bebê ao nascer, com toda sua delicadeza e desproteção, necessita de cuidados especiais para que tenha um crescimento e desenvolvimento saudáveis, razão pela qual a futura mãe necessita ser informada sobre esses cuidados, principalmente as gestantes adolescentes que, muitas vezes, pela idade ou pelas baixas condições sociais, não sabem cuidar nem de si próprias. Acredita-se que a mãe sendo instruída sobre como cuidar de seu bebê vai procurar com menor freqüência os postos de saúde com seu filho doente.

Durante nossa vivência como enfermeiras e acadêmica de enfermagem em postos de saúde e em maternidades, entretanto, percebemos a elevada incidência de mães adolescentes e observamos a inabilidade delas em cuidar de seus filhos. 0 que nos faz questionar se as adolescentes primíparas estão sendo orientadas acerca do cuidado com os bebês.

Então, diante dessas indagações, objetivou-se neste estudo investigar se as adolescentes primíparas estão recebendo orientações acerca do cuidado com seus bebês.

\section{METODOLOGIA}

Trata-se de um estudo do tipo descritivo, com abordagem quantitativa. As pesquisas quantitativas são indicadas quando os dados coletados, em si e por si, não respondem às indagações das hipóteses, por isso precisam ser processados e analisados com alguma forma de estatística. As pesquisas descritivas têm como objetivo primordial a descrição das características de determinada população ou fenômeno ou o estabelecimento de relações variáveis. São inúmeros os estudos que podem ser classificados sob este título e uma de suas características mais significativas está na utilização de técnicas padronizadas de coleta de dados ${ }^{4}$.

0 cenário do referido estudo foi uma maternidade pública em Fortaleza, terciária no atendimento à adolescente no Estado do Ceará, contando com 48 leitos destinados a partos normais e 50 para partos abdominais, realizando em média, 800 partos por mês.

As participantes foram 30 (trinta) adolescentes primíparas, no puerpério imediato, internadas no Alojamento Conjunto da instituição que abrigou o estudo. 
A coleta de dados ocorreu nos meses de setembro e outubro de 2004, por meio de entrevista estruturada. Este instrumento é um método de coleta de dados em que 0 entrevistador faz questionamentos verbais ao sujeito da pesquisa ${ }^{5}$. A entrevista foi subdividida em duas partes, uma delas contendo dados relativos ao perfil socioeconômico das entrevistadas e a outra compreendendo perguntas relativas à temática.

A análise dos dados foi realizada por meio dos achados dos depoimentos obtidos na entrevista. Para melhor visualização e mais fácil compreensão, os dados foram organizados em forma de tabelas, quadros e discussões textuais.

A pesquisa seguiu todos os princípios éticos, conforme Resolução ñ. 196/96, do Conselho Nacional de Saúde estabelece assegurando às participantes o sigilo de suas informações, atentando-se, também, para a necessidade de assinatura de um termo de consentimento livre e esclarecido, o que foi devidamente atendido.

\section{APRESENTACC̃̃ E ÁNALISE DOS RESULTADOS}

Os dados apresentados a seguir foram obtidos por meio de uma entrevista estruturada. Os resultados foram analisados e discutidos à luz da literatura pertinente.

\section{Caracterização do perfil socioeconômico} das participantes da pesquisa

\section{Tabela 1:}

Distribuição das entrevistadas, segundo a idade. Fortaleza 2004

\begin{tabular}{ccc}
\hline Idade & $\mathrm{N}^{0}$ & $\%$ \\
\hline 13 & 1 & 3,3 \\
14 & 3 & 10,0 \\
15 & 1 & 3,3 \\
16 & 7 & 23,3 \\
17 & 5 & 16,8 \\
18 & 7 & 23,3 \\
19 & 6 & 20,0 \\
\hline TOTAL & 30 & 100,0 \\
\hline
\end{tabular}

De acordo com a tabela 1, as participantes do estudo encontravam-se na faixa etária de 13 a 19 anos verificando-se que a maioria contava entre 16 e 19 anos. Cinco tinham a idade menor ou igual a 15 anos, considerada de maior risco ${ }^{6}$.

Um dos fatores associado à gravidez na adolescência é a falta de conhecimento do adolescente sobre as questões sexuais. Os adolescentes continuam mal informados, apresentando falta de compreensão sobre assuntos como o ciclo menstrual, o tempo de fertilidade e o processo de concepção. Acreditam que a fertilidade não começa com a primeira menstruação, o que acarreta a incapacidade de perceber que o risco de gravidez existe desde a primeira relação sexual, e tendem a achar que é necessário que fiquem mais velhos para a gravidez ocorrer ${ }^{7}$.

Quanto ao uso de anticoncepcionais, os adolescentes são mal informados sobre os métodos anticoncepcionais. Porém, a maioria é capaz pelo menos de indicar um desses métodos. Tendem a apresentar, contudo, atitudes negativas sobre o uso do método que é visto como um fator de interferência no prazer sexual. Possuem ainda, crenças errôneas de que os métodos anticoncepcionais são incompatíveis com a baixa freqüência de suas relações sexuais, bem como a idéia de que o uso é de responsabilidade do parceiro ${ }^{8}$.

A menina muito jovem não está preparada para a gravidez, nem física nem psicologicamente, de modo que provavelmente competirá com o feto pelos nutrientes, uma vez que ela também está em fase de desenvolvimento. Além disso, parece haver mais risco de morbidade materna e morbimortalidade neonatal e perinatal, como prematuridade e baixo peso ao nascer.

Tabela 2:

Distribuição das entrevistadas, segundo a escolaridade. Fortaleza, 2004

\begin{tabular}{lcc}
\hline Nível de escolaridade & $\mathrm{N}^{0}$ & $\%$ \\
\hline Ensino fundamental & 5 & 15,0 \\
Ensino fundamental incompleto & 15 & 55,0 \\
Ensino médio completo & 5 & 15,0 \\
Ensino médio incompleto & 5 & 15,0 \\
\hline Total & 30 & 100,0 \\
\hline
\end{tabular}

Com relação à escolaridade pode-se observar na tabela 2, que cinco adolescentes concluíram o ensino médio; cinco tinham o ensino médio incompleto; cinco possuíam certificado do ensino fundamental e quinze cursaram incompletamente o ensino fundamental. Entre elas, apenas duas entrevistadas não interromperam os estudos durante a gravidez e os motivos citados para o abandono dos estudos estavam direta ou indiretamente relacionados à gravidez, o que corroborou o pensamento de alguns autores de que existe associação entre a maternidade precoce e o baixo nível educacional, sendo altas as taxas de evasão escolar quando ocorre uma gravidez ${ }^{9}$.

Assim, com a elevada evasão escolar, essas mulheres não estarão preparadas para enfrentar a 
competição do mercado de trabalho e, possivelmente só terão condições de conseguir empregos com baixos salários, o que dificulta ainda mais sua situação de vida. Outros autores referem que a escolaridade da gestante é um fator que merece atenção, pois fornece subsídios importantes de como conduzir as orientações na assistência pré, trans e pós-natal ${ }^{10}$.

\section{Tabela 3:}

Distribuição das entrevistadas, de acordo com o estado civil. Fortaleza, 2004.

\begin{tabular}{ccc}
\hline Estado Civil & $\mathrm{N}^{0}$ & $\%$ \\
\hline União consensual & 23 & 76,7 \\
Solteira & 6 & 20,0 \\
Casada & 1 & 3,3 \\
\hline TOTAL & 30 & $100 \%$
\end{tabular}

Em relação ao estado civil das adolescentes estudadas, revelou-se, nesse grupo, o predomínio das participantes que viviam em união consensual, 23 $(76,7 \%)$, seguidas de seis solteiras $(20 \%)$, e de uma casada (3.3\%).

A maioria das puérperas adolescentes entrevistadas dizia "estar juntas", ou seja, em união consensual, sem vínculo civil. Sabemos que a Lei assegura os direitos civis da criança sendo os pais casados ou não. Em virtude da instabilidade da jovem, entretanto, essas uniões tendem a ser frágeis e a se desfazer em pouco tempo. A adolescente, ao enfrentar dificuldades na primeira união consensual, busca segurança em outro companheiro constituindo um novo relacionamento, ou retorna aos estudos e/ou trabalho dependendo das condições em que vive e do apoio da família ${ }^{10}$.

Tabela 4:

Distribuição das entrevistadas, de acordo com a renda familiar. Fortaleza, 2004.

\begin{tabular}{lcc}
\hline Renda familiar & N $^{0}$ & $\%$ \\
\hline Mais de um salário mínimo & 11 & 36,7 \\
Igual a um salário mínimo & 7 & 23,3 \\
Menor de um salário mínimo & 6 & 20,0 \\
Não sabe responder & 6 & 20,0 \\
\hline Total & 30 & 100
\end{tabular}

Verifica-se na tabela 4 que a renda familiar de 13 das adolescentes pesquisadas (43,3\%) é igual ou menor do que um salário mínimo. É difícil atender às necessidades básicas de uma família com salário nesse valor. Também é inegável que a gravidez na adolescência, especialmente nas faixas de renda mais baixas, contribui para a perpetuação de um ciclo de pobreza e de carência.

A gravidez precoce repercute assim, na vida pessoal, familiar, social e educacional da adolescente. Do ponto de vista pessoal, ela se defronta com as alterações corporais provocadas pela auto-imagem e auto-estima. Esse estado de autodepreciação é agravado pela insegurança no cuidado com o seu bebê, decorrente de sua inexperiência e imaturidade. Para superar essa dificuldade, é comum a adolescente permanecer vivendo com a família. A maternidade, nessas circunstâncias, ocasiona mudanças na dinâmica familiar, interferindo no padrão do sono, repouso, alimentação, lazer, entre outros. Além disso, em alguns casos, acarreta sobrecarga financeira, que priva as adolescentes de investimentos pessoais. Entre esses investimentos está o processo de educação, freqüentemente interrompido, originando atraso na vida estudantil e distanciamento do grupo de convivência.

Tabela 5:

Distribuição das participantes, quanto à realização das consultas de Pré-natal. Fortaleza, 2004.

\begin{tabular}{lc}
\hline $\begin{array}{l}\text { Número de consultas } \\
\text { no pré-consultas de pré-natal }\end{array}$ & $\mathrm{N}^{\circ}$ \\
\hline Menos de seis & 10 \\
Seis & 9 \\
Mais de seis & 11 \\
\hline Total & 30 \\
\hline
\end{tabular}

Todas as adolescentes entrevistadas compareceram ao serviço de pré-natal em postos de saúde ou em hospitais, dez com um número de consultas insatisfatório. Onze delas estiveram presentes em 6 consultas e nove foram a seis consultas. 0 Ministério da Saúde instituiu o Programa de Humanização no PréNatal e Nascimento (PHPN) em 2000. Segundo este Programa, o serviço de saúde deve realizar a primeira consulta de pré-natal até o quarto mês de gestação. Entre os procedimentos que o programa assegura está a realização de, no mínimo, seis consultas de pré-natal sendo preferencialmente, uma no primeiro trimestre, duas no segundo e três no terceiro trimestre ${ }^{11}$.

A causa dos problemas e/ou patologias que ocorrem na gravidez e/ou parto de adolescentes está relacionada ao início tardio do controle pré-natal e ao número insuficiente de consultas ${ }^{12}$. 
Tabela 6:

Distribuição das participantes, quanto à participação das entrevistadas nas palestras, aulas ou cursos sobre cuidados com o bebê. Fortaleza, 2004

\begin{tabular}{ccc}
\hline Participação nas palestras & $\mathrm{N}^{0}$ & $\%$ \\
\hline Sim & 2 & 6,0 \\
Não & 28 & 94,0 \\
\hline Total & 30 & 100,0
\end{tabular}

Das entrevistadas, cinco relataram que foram convidadas durante as consultas de pré-natal a participar de palestras sobre os cuidados com o bebê. Pode-se observar, porém, que apenas duas tiveram interesse em participar das palestras e se mostraram conhecedoras de como cuidar de seus filhos.

Acredita-se que, com as palestras e/ou cursos oferecidas às gestantes, juntamente com a adesão e 0 interesse das mesmas, haveria benefícios para a saúde dos bebês tendo como conseqüência a baixa procura destas mães aos postos de saúde e hospitais com seus filhos doentes.

\section{Quadro 1:}

Experiência prévia das entrevistadas no cuidado de bebês. Fortaleza, 2004

\begin{tabular}{|lc|}
\hline O que faziam & $\mathrm{N}^{0}$ \\
\hline Brincavam & 10 \\
Preparavam alimentação & 7 \\
Banhavam & 14 \\
Trocavam fralda & 13 \\
Davam medicação & 4 \\
Outros & 6 \\
\hline
\end{tabular}

Entre as adolescentes estudadas, 19 relataram experiência no cuidado com bebês, seja trabalhando como babás, ou cuidando de irmãs mais novas ou sobrinhos, enquanto 11 delas disseram que nunca tiveram prática com bebês. Por meio da literatura sabe-se que, antigamente a menina ajudava a criar alguns bebês irmãos, sobrinhos, primos. Entretanto, em decorrência da redução dos núcleos familiares e do número de filhos, a possibilidade de aprendizagem baseada em experiências próprias está cada vez mais remota ${ }^{13}$.

Durante a entrevista indagou-se a todas se elas gostariam de receber alguma informação ou tirar alguma dúvida sobre como cuidar do bebê. Mas, apenas seis fizeram perguntas, querendo saber a respeito da limpeza do coto umbilical, do teste do pezinho e como posicionar o bebê para "arrotar".
As características peculiares desta fase (em especial no sexo feminino) interferem na forma como a adolescente cuida do filho, sendo a família um suporte necessário para o cuidado da criança. Segundo alguns autores, a mãe da adolescente exerce certa ascendência sobre ela, decidindo "assumir" o neto, no lugar de ajudar a filha nas tarefas da maternidade ${ }^{14}$.

\section{Quadro 2:}

Orientações acerca dos cuidados com os bebês recebidos durante o Pré-Natal. Fortaleza, 2004.

\begin{tabular}{|lc|}
\hline Orientações mais comuns & N $^{0}$ \\
\hline Amamentação & 17 \\
Vacinação & 6 \\
Higiene do bebê & 4 \\
Banho de sol & 3 \\
Não uso de chupetas & 2 \\
Não receberam orientação & 11 \\
\hline
\end{tabular}

0 cuidado materno constitui um conjunto de ações biológicas, psicossociais e ambientais que permitem à criança desenvolver-se bem. Além de ela se achar rodeada de afeição, precisa de um potencial de cuidados e providências a serem adotadas: o sono tranqüilo, a alimentação, a higiene e outros. Reconhecer e saber interpretar corretamente os sinais que o recém-nascido emite é imprescindível para a sua saúde e o seu bem-estar.

Constatou-se a partir do quadro 2, uma escassez de informações. Dezessete delas receberam orientação sobre o aleitamento materno exclusivo até os seis meses de idade. Seis captaram informações sobre a importância da vacinação, quatro foram informadas sobre o banho do recém-nascido, três acerca da importância do banho de sol e como realizá-lo, duas foram orientadas a não dar chupeta e onze não ouviram qualquer orientação. Há inúmeras informações que essas futuras mães deveriam obter para saber como cuidar de seus filhos de maneira correta, tendo mais autonomia e responsabilidade, evitando o surgimento de doenças na criança.

Nessa perspectiva, é de fundamental importância que os profissionais de saúde, ao assistirem as adolescentes primíparas observem o contexto social em que estão inseridas, não se esquecendo de que elas trazem em sua bagagem, conhecimentos, crenças e valores próprios de sua vida pessoal e familiar ${ }^{15}$.

No que diz respeito à consulta adequada ao adolescente constatou-se que, apesar dos importantes 
avanços na organização do sistema de saúde e posteriormente, na atenção à saúde da familia, o atendimento aos adolescentes e aos jovens é limitado, principalmente pela carência de profissionais capacitados e pela falta de apoio para o acompanhamento da população nesta faixa etária ${ }^{16}$.

\section{Quadro 3:}

Orientações recebidas durante a permanência no Alojamento Conjunto, acerca dos cuidados com o bebê. Fortaleza, 2004.

\begin{tabular}{|lc|}
\hline Orientações mais freqüentes & $\mathrm{N}^{0}$ \\
\hline Amamentação & 26 \\
Limpeza do coto umbilical & 17 \\
Prevenir assaduras & 4 \\
Banho do bebê & 2 \\
Não recebeu orientação & 4 \\
\hline
\end{tabular}

Conforme autores, o desempenho da mãe no alojamento conjunto, nos cuidados com o bebê, deve ter uma conotação ativa, de sorte que a educação é fundamental ${ }^{18}$. 0 quadro 3 mostra que, entre as entrevistadas, 26 disseram haver sido orientadas quanto ao aleitamento materno e terem recebido ajuda da enfermeira quando não estavam conseguindo amamentar; 17 foram orientadas na realização da higiene do coto umbilical; 4 receberam orientação sobre o cuidado com a troca de fraldas no sentido de prevenir assaduras; e 2 disseram ter sido orientadas na higiene do bebê. Quatro responderam, pórem, que não Ihes foi passada nenhuma informação. Isto chamou a atenção, pois o alojamento conjunto é o sistema de atendimento do recém-nascido junto à mãe visando a promover o relacionamento mãe-filho-equipe de saúde e habilitando a mãe nos cuidados ao recém- nascido, além de fortalecer as ligações afetivas mãe-filho ${ }^{18}$.

Logo, o sistema de Alojamento Conjunto surgiu da necessidade de criar condições que propiciassem relacionamento favorável entre a mãe e o recémnascido, desde os primeiros momentos após o parto. A mãe sente-se mais tranqüila quando tem o filho ao seu lado, pois pode observá-lo e atendê-lo sempre que necessário ${ }^{19}$.

Portanto, o sistema de Alojamento Conjunto deve preencher os objetivos psicológicos, nutricionais, educacionais, físicos, razão pela qual ele é acompanhado de uma série de vantagens, não só para ao binômio mãe e filho, como também para o hospital e para a equipe de saúde ${ }^{20}$.

\begin{tabular}{|c|c|c|}
\hline \multicolumn{3}{|c|}{$\begin{array}{l}\text { Tabela 7: } \\
\text { Orientações recebidas de familiares e amigos. }\end{array}$} \\
\hline Orientações dos familiares & $\mathrm{N}^{0}$ & $\%$ \\
\hline Sim & 20 & 97,0 \\
\hline Não & 10 & 3,0 \\
\hline Total & 30 & 100,0 \\
\hline
\end{tabular}

Das adolescentes entrevistadas neste estudo, 20 relataram haver recebido orientação de pessoas da família e amigos, suas mães, irmãs e cunhadas. E 10 delas disseram não ter obtido nenhuma orientação.

Pesquisadores revelam que as orientações recebidas pelas adolescentes nos postos de saúde, muitas vezes, deixam de ser praticadas, em razão da falta de sua autonomia em cuidar de seus filhos ${ }^{14}$. Elas alegaram que ninguém acreditava no que sabiam. Os cuidados com 0 bebê ensinados pelos profissionais de saúde, não eram os mesmos empregados na prática significando que as orientações recebidas em casa por familiares nem sempre estavam corretas, o que mostrou que essas mães adolescentes necessitavam de conhecimentos, para terem mais segurança e autonomia.

\section{CONSIDERAÇÕES FINAIS}

A preocupação das autoras voltou-se para as adolescentes primíparas por considerarem que elas, ao vivenciarem uma fase de transição, que também se configura como em um momento de crise, passam por uma metamorfose caracterizada como uma passagem entre a infância e a vida adulta.

Como vimos, adolescência é uma faixa etária bastante vulnerável tanto pelas características próprias da idade, como por fatores provenientes do mundo externo, entre os quais sua inexperiência em lidar com os próprios sentimentos e os do parceiro. Também, há de se levar em conta a ausência de certas habilidades, como a de cuidar do seu próprio filho, por exemplo.

Os resultados deste estudo apontaram que as puérperas adolescentes são carentes de orientações e esclarecimentos acerca dos cuidados com o bebê. Esperam contar com a ajuda dos pais e da família, pois este grupo social de ordem primária apresenta-se como apoio para essas adolescentes. Constatou-se ainda que, apesar de freqüentarem o posto de saúde para a realização do pré-natal, faltou por parte deste serviço, pessoal que trabalhasse na adesão das gestantes, no sentido de incentivá-las a participar das palestras oferecidas e/ou o chamamento para as palestras não está conseguindo chegar às adolescentes. 
Nesse contexto, sugere-se que o poder público e a Enfermagem empenhem-se na divulgação de informações sobre a contracepção, visto que as adolescentes engravidam sem planejamento, por falta de informação, do desconhecimento dos métodos anticoncepcionais e de educação sexual, fatores exacerbados pela dificuldade de acesso a serviços especializados com profissionais de saúde francamente comprometidos e especializados no atendimento dessa clientela especifica.

\section{Referências}

1.Organização Mundial da Saúde- OMS. Maternidade segura. Assistência ao parto normal: um guia prático. Genebra: 1996.

2. Cavalcanti SMOC, Amorin MMR, Santos, LC. 0 significado da gravidez para a adolescente. Revista Feminina 2001 abr; 29 (5) 311 - 314.

3. Polit DF, Hungler BP. Fundamentos de Pesquisa Social. São Paulo: Atlas; 1999

4.Gil AC. Métodos e técnicas de pesquisa social. São Paulo (SP): Atlas; 1999.

5.Wood GL, Habeer Pesquisa em enfermagem: métodos, avaliação crítica e utilização. $4^{\text {a }}$ ed . Rio de Janeiro (RJ): Guanabara Koogan; 2001.

6. Brandem OS. Enfermagem materno-infantil. $2^{\mathrm{a}} \mathrm{ed}$. Rio de Janeiro (RJ): Reichamnn \& Affonso ; 2000.

7.Boruchovitch E. Fatores associados à não utilização de anticoncepcionais na adolescência. [on line] [Citado em: 01 jun 2004]. Disponível em: URL:http// www.scielo.br/scielo

8. Hirata MC. Proposta de intervenção sobre o problema de gravidez na adolescência: uma contribuição do enfoque estratégico-situacional do planejamento. Rev Baiana Enferm 1994 abr / out; 7 (1/2): 133-52.

9. Martins RM, Pessoa SM, Sousa RA. Perfil de um grupo de adolescentes quejá experenciaram a maternidade. Rev RENE 2002 jul/dez; 3 (2): 65-70.

10. Mello M, Lima J V. Humanização do parto em adolescentes: aspectos emocionais. RECCS 2002 abr-jun; 15 (2): 11-15.

11. Makuch M, Dias M, Oliveira J, Cabral F. Grupo de apoio para adolescentes arávidas: uma estratégia para melhorar a atenção prénatal. Rev Femina 2001; 29 (8): 545-49

12. Sofier R. Psicologia da gravidez, parto e puerpério. Porto Alegre (RS): Artes Médicas; 1991.

13. Machado FN,Madeira AM. Percepções da família sobre a forma como a adolescente cuida do filho. Rev Esc Enferm USP 2003; 37(1):11-18.

14. Barroso L MM, Victor JF. Qualidade dos serviços ap cliente e dos serviços de apoio em unidade básica de saúde da família. Rev RENE2003 jan/jun; 4 (1): 24-29.

15. Jácomo AJD, Marinice C, Midlej J, Lisboa AMJ. Assistência ao recémnascido, normas e rotinas. $3^{\mathrm{a}}$ ed. São Paulo (SP): Atheneu; 1996.

Esc Anna Nery R Enferm 2005 dez; 9 (3): 365 - 71
16. Tyrrel MAR, Santos FRP. A asssistência à mulher no pré-parto e parto na perspectiva da maternidade segura. Esc Ana Nery Revista Enferm $2005 \mathrm{abr}$; 9(1): 46-53.

17.Pizzato, M,Da Poian, VRL. Enfermagem neonatológica. Porto Alegre(SP): Luzato; 1998

18. Vaz FAC, Gualda DMR. Alojamento conjunto.In: Leone CR, Tronchin DMR .Assistência integrada ao recém-nascido. São Paulo (SP): Atheneu; 2001. p.43-49.

19. Figueira B, Costa H, Casanova L, Lippi U. Considerações sobre alojamento conjunto. Rev Pediatria Atual 1998;11(10): 13-18.

20. Ministério da Saúde (BR). Secretaria de Políticas de Saúde.Área Técnica de Saúde da Mulher. Parto, Aborto e Puérperio: assistência humanizada à mulher. Brasília (DF): 0 Ministério: 2001.

\section{Sobre as Autoras}

Dayane Cristina de Sousa Rocha Enfermeira graduada pela Universidade de Fortaleza-UNIFOR.

Maria Gorette Andrade Bezerra

Enfermeira da Maternidade-Escola Assis Chateaubriand-MEAC/UFC. Mestra em Enfermagem. Docente do Curso de Enfermagem da Universidade de Fortaleza-UNIFOR. Membro integrante do Projeto de Saúde do Binômio Mãe-Filho/UFC.

Antonia do Carmo Soares Campos

Enfermeira da UTI-Neonatal da MEAC/UFC. Doutora em Enfermagem. Docente do Curso de Enfermagem da Universidade de FortalezaUNIFOR. Membro integrante do Projeto de Saúde do Binômio MãeFilho/UFC. E:mail: ankardagostinho@terra.com.br 